\title{
Payment for performance in health care
}

\section{Debates about performance related pay seem to have moved on from whether it is desirable to how to make it work. But Russell Mannion and Huw Davies caution that we still don't know enough about the potential problems}

Health service pay is top of the political and media agenda in many countries. In the UK, moral outrage over doctors' pay - fuelled by the lay media - has contributed to a widespread belief that pay rises have soaked up much of the recent investment in the NHS. ${ }^{1}$ Doctors' representatives respond that rising pay reflects rising quality and performance, but doubts remain and even the government has expressed alarm, threatening to cap future rises. Other countries are also grappling with how to pay healthcare professionals, particularly doctors.

\section{Pay and performance}

Many countries have linked the remuneration problem with concerns about quality and performance, focusing new attention on payment for performance programmes. Under these programmes a portion of payment is dependent on performance assessed against one or more defined measures. ${ }^{2}$ The United States has over 100 private and federal Medicare reward and incentive programmes, ${ }^{3}$ and Italy and New Zealand are beginning to reward performance in primary care. The UK remains in the vanguard of such schemes, with the quality and outcomes framework paying out around $£ 1000 \mathrm{~m}(€ 1300 \mathrm{~m} ; \$ 2000 \mathrm{~m})$ in 2005-6 to general practices ${ }^{4}$ and being described at its launch as the "boldest such proposal on this scale ever attempted anywhere in the world." 5

Paying for performance is being given increasing attention across many public services, as a means of motivation and drawing attention to local agency. ${ }^{6}$ Beyond these larger trends, many reasons have been

\section{Russell Mannion director, Centre for Health and Public Services Management, University of York, York Y010 5DD \\ Huw T O Davies director, Social Dimensions of Health Institute Universities of Dundee and St Andrews \\ Correspondence to: R Mannion rm15@york.ac.uk}

Accepted: 14 November 2007

Box 1 | Why link financial rewards to quality and performance?

- Desire to curb costs; enhance quality, safety, and access; and reduce variations in health care

- Accumulating evidence that better processes of care (timely use of diagnostics, appropriate use of treatments, etc) will improve patient outcomes

- Present payment arrangements do not reward quality or performance and may provide disincentives in some clinical areas ${ }^{3}$

- Perceptions that intrinsic motivations (such as professionalism) alongside weak self regulation have been insufficient to tackle failings in quality and performance ${ }^{7}$

- Recent theories from psychology, economics, and organisational behaviour highlighting the use of incentives

- Emergence of systems to measure quality and performance and ability to extract detailed data

- Perceptions that indirect incentives implicit in public reporting of quality of health care have not produced desired improvements ${ }^{2}$

- Evidence from other industries and public services that linking financial incentives to performance can improve service quality ${ }^{2}$

- Previous limited efforts linking doctors' pay to the quality of care had positive outcomes, including increased immunisation rates and geographical equity ${ }^{9}$

- Doctors' gradual acceptance that quality of care can be measured and that pecuniary incentives have a role in securing high quality services

given for linking doctors' pay to performance (box 1). Taken together, these arguments have contributed to a lessening of ideological debate with much of the deliberation now being confined to the practicalities of implementation.

Pay for performance is based on the bold hope that the incentives offered will enhance desired behaviours with few unwanted effects in other areas. Yet much of the underpinnings of pay for performance are contestable at best, and the evidence supporting its benefits is inconclusive. We therefore need to consider the possible consequences of new programmes before they are introduced and monitor their effects after they are implemented. Analysis of existing schemes is informative in this respect.

\section{Design elements of pay for performance systems}

Payment for performance schemes operate in many different ways, but they share common and fundamental features. Most of the potential designs have already been used in one form or another, and many of them require important trade-offs, the relative impacts and risks of which are currently unknown. Some of the core design choices are elaborated below.

\section{Objectives}

The objectives and targets expressed in a pay for performance system are the goals against which progress against achievement is assessed. Although most schemes focus on quality, performance objectives could cover a wide range of variables including volume, equity, patient satisfaction, patient safety, and cost effectiveness. ${ }^{2}$

\section{Unit of assessment}

Pay for performance schemes vary in terms of who receives financial incentives. Rewards could be targeted at individual clinicians, clinical teams, or larger organisational units. In theory, rewards should be paid to those responsible for delivering improved performance, but in practice attribution is difficult because of the interlocking nature of much health care. Most schemes have focused on rewarding groups of practitioners, such as a primary care practice.

\section{Performance measures}

A fundamental decision is whether to focus on measures of process or outcome. Although clinical outcomes link more closely with the objectives of a health system, it is often not feasible to collect and disseminate such data in time for incentive payments. 


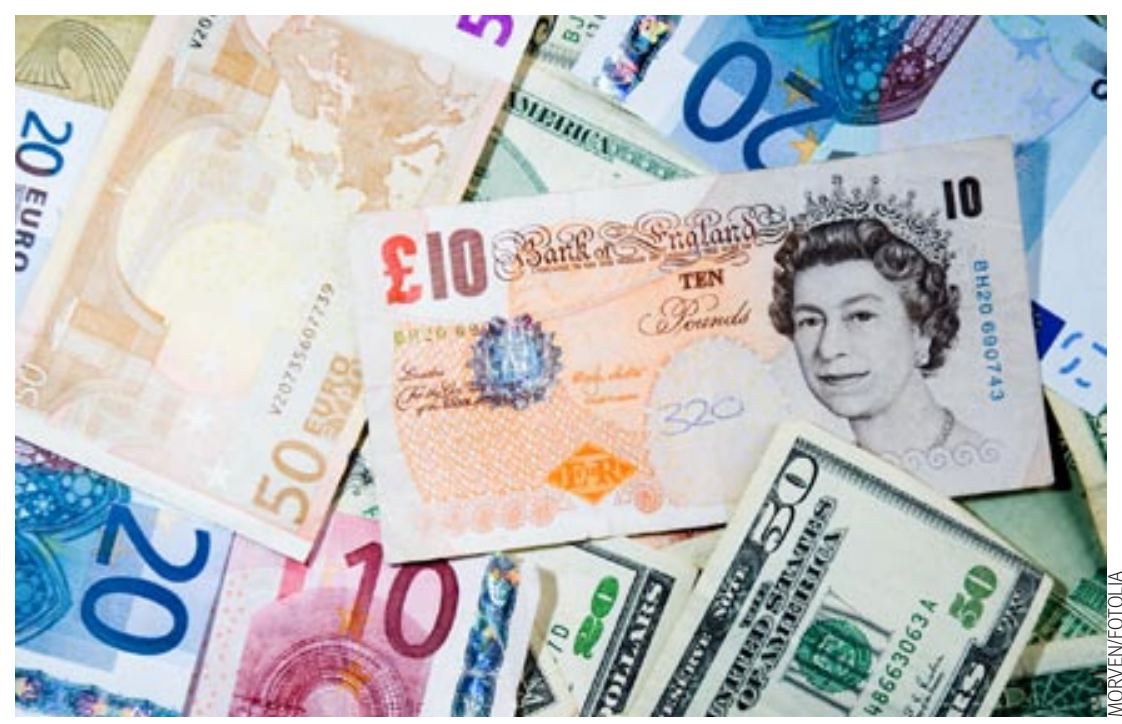

Analysis and interpretation of performance data

To attribute poor measured performance to poor actual performance it is necessary to make causal inferences from observed data. However, because of the high interdependency of health systems many external factors weaken the link between actual performance and measured performance (not least case mix and chance variability). Raw data therefore has to be adjusted to take into account the confounding effects of external circumstances and case mix. Such adjustment can itself be controversial.

\section{Performance standards}

The performance criteria or thresholds used to determine whether payments are triggered. may be absolute or relative. Absolute standards (such as specific targets for key measures) have the advantage that there is no uncertainty over whether a standard has been met. ${ }^{2}$ Relative standards (such as rewards for high positioning in league tables and rankings) focus instead on performance relative to peers. These approaches can be used selectively-for example, to reward improvement rather than position-because high performing providers may have little opportunity to improve their relative position.

\section{Financial rewards}

The size of the financial reward provided by a pay for performance scheme is perhaps the key factor motivating changes in behaviour. If the reward is small the effect may be negligible. Conversely, large incentives may lead to major, potentially unpredictable, changes. As rewards rise, so does the risk of adverse consequences. Responses may also be influenced by whether the performance payments are a potential gain or a potential loss. Current schemes for primary care in New Zealand place at risk only a small percentage of total payments, whereas the UK quality and outcomes framework theoretically puts at risk up to a quarter of practice income.

The effects of pay for performance (good and bad) may depend on these detailed design choices, making generalisations from one design to another problematic. For example, schemes that focus on individuals may work differently from those aimed at practices or hospitals.

\section{Current knowledge}

Evaluation of pay for performance initiatives has not kept pace with the rush to implement them. The limited number of evaluations are typically small scale and are of designs from which it is difficult to generalise, particularly outside the US. One recent review of the evidence base to support pay for performance found only seven published studies and concluded that, despite the enthusiasm of its proponents, the empirical foundations of paying for performance in health care are rather weak. ${ }^{10}$

A second systematic review used broader search and inclusion criteria, identifying 17 studies; it concluded that the literature suggested some possible modest positive effects of financial incentives. ${ }^{11}$ These include cost savings to the Medicaid programme from shorter nursing home stays ${ }^{12}$; small improvements in cervical cancer screening; and improved immunisation rates. ${ }^{13}$ However, several studies found either no effect $^{14}$ or negative effects, such as reduced access to health care for the most severely ill patients. ${ }^{15}$ They also noted a tendency towards improvements in documentation of care rather than a change in the actual quality of care. ${ }^{16}$ The authors stress that most of the studies reviewed were merely descriptions rather than robust systematic evaluations of pay for performance schemes and that their findings may have been affected by publication bias given the disincentives for healthcare executives to publish negative findings of such schemes. ${ }^{11}$

In the UK an assessment of the first year of the quality and outcomes framework in primary care found that family practitioners attained $98 \%$ of the available points for clinical indicators. ${ }^{17}$ This was much higher than the $75 \%$ expected when the scheme was negotiated, resulting in an increase of $£ 23000$ in the gross income of the average family practitioner at high cost to the tax payer. Thus, whereas the framework places a theoretically high proportion of practice income at risk (around 25\%), in practice most practices secured almost the full amount.

High scores on the quality and outcome framework

Box 2 | Potential unintended effects of pay for performance

- Tunnel vision-a focus on aspects of clinical performance that are measured and neglect of unmeasured areas ${ }^{18}$

- Adverse selection-the incentive to avoid the most severely ill patients

- Erosion-the potential diminution-of intrinsic professional motivation as a key attribute of high quality health care $^{19}$

- Inequity-creation of perverse incentives to exclude disadvantaged groups ${ }^{20}$

- Over compensation-rewarding providers who already meet or exceed the target threshold

- Misreporting, gaming, or fraud ${ }^{18}$ 
might have partly resulted from gaming. Some practices seemed to have achieved high scores by excluding large numbers of patients, although it was unclear whether these exclusions were for sound clinical reasons or in order to maximise income. ${ }^{4}$ Even if family practitioners have not played the system, there is a widespread concern that the targets were too easy to attain and in some cases rewarded quality improvements that had already taken place. ${ }^{4}$ Moreover, at least $80 \%$ of primary care work is not covered by the framework and thus has no financial incentive. Such experience should caution against too high expectations about value for money and highlights the potential for ceiling effects when schemes are not carefully calibrated.

Recent evaluation of the quality and outcomes framework in Scotland suggests that practices delivered higher quality than that required to maximise their financial income. ${ }^{4}$ The behavioural drivers thus seem to go beyond the financial reward and may include, for example, professionalism, pride, or differentiating the practice from local peers. ${ }^{4}$

\section{Getting benefits without problems}

Pay for performance in health care is based on a whole set of assumptions of uncertain validity and strength:

- Financial incentives will motivate behavioural change

- Such behavioural change will deliver the desired improvements in quality and performance

- Policy makers can distinguish between those aspects of clinical activity that would benefit from financial incentives and those that would be affected adversely

- The net benefits outweigh any unintended and unwanted responses (box 2).

Avoiding potential harms may not be easy and will require a strong evidence base on all the potential outcomes of schemes (box 3). Schemes should be viewed as dynamic systems that need to be tailored to the needs of different professional groups, services, and patients. All stakeholders should participate in setting up new schemes and pilots should be independently evaluated. Once established, schemes will need constant trimming, recalibrating, and balancing to ensure that their objectives are being met at the right cost and without too many unwanted effects. One important approach will be to ensure a balanced selection of measures, thus preventing a focus on rewarded areas at the expense of other important dimensions of performance; another will be to vary the measures that are included year to year. Finally, we might think about schemes that reward

Box 3 | Building evidence on good and bad effects

- Research the motivational drivers of healthcare professionals and how these can be harnessed for the social good

- Distil the international and cross sectoral experience with pay for performance

- Pilot new schemes before rolling out nationally

- Evaluate the economics of new programmes to assess whether benefits outweigh costs

- Assess how schemes affect intangible aspects of health care, including professional values and cultures, trust relationships, and patient interaction

- Monitor to ensure that specific patient groups are not discriminated against with truly additional money that is spent collectively by practitioners in partnership with local service users, thus drawing on collective rather than individual models of motivation.

\section{Drawing conclusions}

As yet, we have insufficient evidence to understand what works, under what circumstances, and with what intended and unintended consequences. Although emerging evidence suggests that pay for performance may help shape high performance delivery systems, there are also big pitfalls and therefore risks that such schemes will cost much and deliver little. The challenges that remain are not merely the technical aspects of design but go to the heart of the ideological debate over performance motivation.

We thank Steve Harrison, lan Greener, and Hans Birk for their comments.

Contributors and sources: RM and HD each have over 20 years experience of healthcare research and both direct academic organisations at the forefront of health policy analysis in the UK. Both authors wrote the article; RM is guarantor.

Competing interests: None declared.

Provenance and peer review: Not commissioned; externally peer reviewed.

1 Maynard A. Is doctors' self interest undermining the National Health Service? BMJ 2007;334:234.

2 Hahn J. Pay for performance in health care. Washington, DC: Library of Congress, 2006.

3 Institute of Medicine. Rewarding provider performance: aligning incentives in Medicare. Washington DC: National Academy Press, 2007.

4 Gravelle H, Sutton M, Ma A. Doctor behaviour under a pay for performance contract: evidence from the quality and outcomes framework. (CHE Research Paper 28). York: University of York, 2007.

5 Shekelle P. New contract for general practitioners. BMJ 2003;326:457-8.

6 Le Grand J. Motivation, agency and public policy: of knights and knaves, pawns and queens. Oxford: Oxford University Press, 2003.

7 Institute of Medicine. Crossing the quality chasm: a new health system for the 21st century. London: IoM, 2001.

8 Frey BS. Notjust for the money: an economic theory of personal motivation. Cheltenham: Edward Elgar, 1997.

9 Roland M, Campbell S, Bailey N, Whalley D, Sibbald B. Financial incentives to improve the quality of primary care in the UK: predicting the consequences of change. Primary Health Care Res Dev 2006;7:18-26.

10 Rosenthal MB, Frank RG, Li Z, Epstein AM. Early experience with payfor-performance: from concept to practice. JAMA 2006;294:1788-93.

11 Peterson LA, Woodard LD, Urech T, Daw C, Sookanan S. Does pay for performance improve the quality of care? Ann Intern Med 2006;145:265-72.

12 Norton EC. Incentive regulation of nursing homes. J Health Econ 1992;11:105-28.

13 Fairbrother G, Siegal MJ, Friedman S, Kory PD, Butts GC. Impact of financial incentives on documented immunization rates in the inner city: results of a randomized control trial. Ambul Pediar 2001;1:206-12.

14 Hillman AL, Ripley K, Goldfarb N, Nuamah I, Weiner J, Lusk E. Physician financial incentives and feedback: failure to increase cancer screening in Medicaid managed care. Am J Public Health 1998:88:1699-701.

15 Shen Y. Selection incentives in a performance-based contracting system. Health Serv Res 2003;38:535-52.

16 Roski J, Jeddeloh R, An L, Lando H, Hannan P, Hall C, et al. The impact of financial incentives and a patient registry on preventative care quality: increasing provider adherence to evidence based smoking cessation practice guidelines. Prev Med 2003;36:291-9.

17 Doran T, Fullwood C, Gravelle H, Reeves D, Kontopantelis E, Hiroeh U, et al. Pay for performance programs in family practices in the United Kingdom. N Engl J Med 2006;355:375-84.

18 Smith PC. On the unintended consequences of publishing performance data in the public sector. IntJ of Pub Admin 2006;18:277-310.

19 McDonald R, Harrison S, Checkland K, Campbell S, Roland M. Impact of financial incentives on clinical autonomy and internal motivation in primary care: an ethnographic study. BMJ 2007;334:1357-9.

20 Bierman A, Clark J. Performance measurement and equity. BM 2007;334:1333-4. 